\title{
The correlation between diverticulosis and redundant colon
}

\author{
Tahleesa Cuda ${ }^{1,2}$ (D) Ronny Gunnarsson ${ }^{1,3,4} \cdot$ Alan de Costa ${ }^{1,2}$
}

Accepted: 30 August 2017 / Published online: 20 September 2017

(C) The Author(s) 2017. This article is an open access publication

\begin{abstract}
Background Diverticulosis and redundant colon are colonic conditions for which underlying pathophysiology, management and prevention are poorly understood. Historical papers suggest an inverse relationship between these two conditions. However, no further attempt has been made to validate this relationship. This study set out to assess the correlation between diverticulosis and colonic redundancy.

Methods Redundant colon, diverticulosis and patient demographics were recorded during colonoscopy. Multivariate binary logistic regression was performed with redundant colon as the dependent variable and age, gender and diverticulosis as independent variables. Nagelkerke $R^{2}$ and a receiver operator curve were calculated to assess goodness of fit and internally validate the multivariate model.

Results Redundant colon and diverticulosis were diagnosed in 31 and 113 patients, respectively. The probability of redundant colon was increased by female gender odds ratio (OR) 8.4 (95\% CI 2.7-26, $p=0.00020)$ and increasing age OR 1.7 (95\% CI 1.1-2.6, $p=0.017)$. Paradoxically, diverticulosis
\end{abstract}

Tahleesa Cuda

tahleesa.cuda@my.jcu.edu.au

1 Cairns Clinical School, College of Medicine and Dentistry, James Cook University, Cairns, QLD 4870, Australia

2 Department of Surgery, Cairns Private Hospital, Cairns, QLD, Australia

3 Research and Development Unit, Primary Health Care and Dental Care, Southern Älvsborg County, Region Västra Götaland, Vänersborg, Sweden

4 Department of Public Health and Community Medicine, Institute of Medicine, The Sahlgrenska Academy, University of Gothenburg, Gothenburg, Sweden strongly reduced the probability of redundant colon with OR of 0.12 (95\% CI $0.42-0.32, p=0.000039$ ). The Nagelkerke $R^{2}$ for the multivariate model was 0.29 and the area under the curve at ROC analysis was 0.81 (95\% CI 0.73-0.90 $p$-value $\left.3.1 \times 10^{-8}\right)$.

Conclusions This study found an inverse correlation between redundant colon and diverticulosis, supporting the historical suggestion that the two conditions rarely occur concurrently. The underlying principle for this relationship remains to be found. However, it may contribute to the understanding of the aetiology and pathophysiology of these colonic conditions.

Keywords Diverticulosis · Redundant colon $\cdot$ Acquired megacolon $\cdot$ Idiopathic megacolon $\cdot$ Colonoscopy

\section{Introduction}

Diverticulosis and redundant colon are colonic conditions posing significant morbidity and mortality risks for those affected $[1,2]$. Despite this, the pathophysiological mechanisms, management and prevention of these conditions are not well understood $[3,4]$.

\section{Diverticulosis}

Diverticulosis is the most common pathological condition of the colon, affecting $10 \%$ of individuals under the age of 40 years and $50-70 \%$ of those greater than 80 years of age. Suggestions of altered connective tissue and enteric neuropathy exist, although the exact pathological mechanisms remain unknown [5-9].

Diverticulosis pertains to the presence of the colonic diverticula, regardless of clinical significance. Symptomatic uncomplicated diverticular disease has been attributed to 
short-lived abdominal pain, distension and irritable bowel syndrome-like symptoms $[10,11]$.

\section{Redundant colon}

In contemporary practice, endoscopists, radiologist and surgeons alike frequently note the presence of a 'redundant colon' [12-29]. Hanson et al. (2007) defined redundant colon as an elongated or tortuous colon or in the presence of two or more acute flexures [14]. Raahave et al. (2009) recorded colonic redundancy as a sigmoid loop rising above the iliac crests, transverse colon below iliac crests, supernumerary loops of left and right colonic flexures or a combination of these. This study also described increasing symptoms and colonic transit time with increasing numbers of redundant loops of bowel [15].

The term describes the presence of a chronically distended, elongated and tortuous colon, with no obvious cause [30-34]. Validated diagnostic criteria for the diagnosis of a redundant colon remain elusive. Its clinical significance is not readily appreciated or understood. The condition can involve any part or the entire colon, most commonly affecting the sigmoid [30, $32,33,35,36]$. Commonly associated symptoms include constipation and gas distress [30, 35-37]. The role of surgical management is debatable, except in instances of acute complications. Its presence is loosely associated with colonic volvulus [36, 38, 39]. Whether it consists of a heterogenous group of conditions or is due to a single cause is unknown [40]. Varying enteric neurochemical and histological findings have been suggested [41-51]. Publications on redundant colon are largely low-level evidence case reports, case series and cohort studies.

While colonoscopy is not a validated tool to diagnose the presence of colonic redundancy, endoscopists often identify the condition in the presence of tortuosity, flaccidity and difficulty maintaining insufflation $[14,35,37]$.

\section{The correlation between diverticulosis and redundant colon}

Two historical papers, Ewing (1975) and Goulston (1976), suggested a low incidence of diverticulosis with redundant colon [31, 31, 52]. A common belief also exists among many gastroenterologists and general surgeons that diverticulosis and redundant colon are two conditions rarely seen together. However, no further attempts have been made to substantiate this observation.

This study set out to assess if an inverse relationship exists between diverticulosis and redundant colon. If such a correlation is demonstrated, it may indicate that mechanisms exist leading to the development of one condition and not the other.

\section{Methods}

The James Cook University Human Research Ethics Committee approved this study (approval number H5759) and it was performed in accordance with the recommendation of the Declaration of Helsinki (Edinburgh revision, 2010). Individual consent was obtained from all participants.

\section{Study design}

This was a prospective study performed over 11 months of patients undergoing colonoscopy with participating endoscopists at the Cairns Private Hospital and Cairns Day Surgery, located in Cairns, Australia. Three endoscopists participated in this project - two general surgeons and one gastroenterologist. Each endoscopist had a minimum of 10-year experience.

\section{Eligibility criteria}

Patients undergoing colonoscopy with a participating endoscopist between July 2014 and June 2015, greater than 15 years old, were invited to participate. Those with incomplete data or with a history of colectomy or colostomy were excluded.

\section{Data measurement and bias}

Patients were invited to participate by mail. The presence of redundant colon was recorded as either present or absent. The diagnosis of redundant colon was based upon a subjective finding by the endoscopist of an excessively tortuous, elongated, flaccid or difficult to insufflate colon.

\section{Statistical analysis}

Multivariate binary logistic regression was performed with redundant colon as the dependent variable and gender, age in decades and the presence of diverticulosis as independent variables. Nagelkerke's $R^{2}$ was calculated to evaluate the goodness of fit to the logistic regression model. To internally validate the multivariate model, we constructed a receiver operator curve (ROC) estimating the area under the curve with 95\% confidence interval. Data analysis was performed in SPSS version 22.0 (IBM Corp, Armonk, NY).

\section{Results}

Of 793 patients undergoing colonoscopy, 195 were included in final data analysis (Fig. 1).

Diverticulosis was diagnosed in $113(58 \%)$ of patients. Redundant colon was diagnosed in 31 (16\%) patients. The 




Fig. 1 Outcomes of patient recruitment

probability for redundant colon was increased by female gender with odds ratio (OR) 8.4 (95\% CI 2.7-26, $p=0.00020$ ) and age in decades with OR 1.7 (95\% CI 1.1-2.6, $p=0.017)$. The probability for redundant colon was strongly reduced by the presence of diverticulosis with an OR of 0.12 (95\% CI $0.42-0.32, p=0.000039)$. The Nagelkerke $R^{2}$ for the multivariate model was 0.29 and area under the curve at ROC analysis was $0.81\left(95 \%\right.$ CI $0.73-0.90 p$-value $\left.3.1 \times 10^{-8}\right)$.

\section{Discussion}

This study verifies the suggestion by Ewing (1975) and Goulston (1976) that the redundant colon and diverticulosis rarely occur concurrently. Based on this study, one can predict the likelihood of a redundant colon occurring in an elderly female without diverticulosis is very high. Comparatively, identifying colonic redundancy in a male with diverticulosis is unlikely. This strong inverse correlation suggests that mechanisms involved with either redundant colon or diverticulosis may protect or impede the development of the other condition. Furthermore, this may provide clues to the pathogenesis.

\section{Methodological discussion}

Patient recruitment for this project was difficult from the outset and throughout. Patient participation required active patient completion of a written consent form that was mailed to them. Unfortunately, in-hospital recruitment could not be performed due to both staffing and ethical restraints. A $30 \%$ response rate was obtained. Despite this lower response rate, this study recruited sufficient patients to meet sample size calculations and produce a statistically significant finding.

A validated diagnosis for redundant colon does not yet exist. Colonoscopy is an unvalidated, dichotomous and subjective method to diagnose redundant colon. Endoscopists describe the finding based on their own clinical discretion. Another pitfall of colonoscopy-based diagnosis of redundant colon is the inability to quantify the findings into mild, moderate or severe. Such diagnoses require modalities with physically measurable outcomes - such as radiological imaging or at laparotomy. Some radiological methods such as CT colonography allow for standardized, quantitative diagnoses, which are reproducible between clinicians.

\section{Conclusion}

This study found a statistically significant inverse correlation between the presence of colonic redundancy and diverticulosis during colonoscopy. This finding is in keeping with the suggestions of Ewing (1975) and possibly Goulston (1976) that the two conditions are rarely observed occurring in a single patient. Whether the pathophysiology of colonic redundancy is 'protective' against the development of diverticulosis or likewise, it cannot be extrapolated from this study. Further studies unveiling the underlying mechanism for this inverse correlation may also shed light on the pathogenesis of diverticulosis.

Acknowledgements We are grateful to Dr. Pieter Prinsloo, Dr. Bernard Chin, Cairns Private Hospital, Cairns Day Surgery and James Cook University for their ongoing support and involvement in this study.

Funding Funding research number JCU-QLD-417851 James Cook University Honours Research Department.

Compliance with ethical standards The James Cook University Human Research Ethics Committee approved this study (approval number H5759) and it was performed in accordance with the recommendation of the Declaration of Helsinki (Edinburgh revision, 2010). Individual consent was obtained from all participants.

Conflict of interest The authors declare that they have no conflict of interest.

Open Access This article is distributed under the terms of the Creative Commons Attribution 4.0 International License (http:// creativecommons.org/licenses/by/4.0/), which permits unrestricted use, distribution, and reproduction in any medium, provided you give appropriate credit to the original author(s) and the source, provide a link to the Creative Commons license, and indicate if changes were made.

\section{References}

1. Gladman MA, Scott SM, Lunniss PJ, Williams NS (2005) Systematic review of surgical options for idiopathic megarectum and megacolon. Ann Surg 241(4):562-574. https://doi.org/10. 1097/01.sla.0000157140.69695.d3

2. Bohm SK (2015) Risk factors for diverticulosis, diverticulitis, diverticular perforation, and bleeding: a plea for more subtle history 
taking. Viszeralmedizin 31(2):84-94. https://doi.org/10.1159/ 000381867

3. Tursi A (2016) Diverticulosis today: unfashionable and still underresearched. Ther Adv Gastroenterol 9(2):213-228. https://doi.org/ $10.1177 / 1756283 \times 15621228$

4. Gladman MA, Knowles CH (2008) Novel concepts in the diagnosis, pathophysiology and management of idiopathic megabowel. Color Dis 10(6):531-538; discussion 538-540. https://doi.org/10. 1111/j.1463-1318.2007.01457.x

5. Whiteway J, Morson BC (1985) Elastosis in diverticular disease of the sigmoid colon. Gut 26(3):258-266

6. Wess L, Eastwood MA, Wess TJ, Busuttil A, Miller A (1995) Cross linking of collagen is increased in colonic diverticulosis. Gut 37(1): 91-94

7. von Rahden BH, Germer CT (2012) Pathogenesis of colonic diverticular disease. Langenbeck's Arch Surg 397(7):1025-1033. https:// doi.org/10.1007/s00423-012-0961-5

8. Macbeth WA, Hawthorne JH (1965) Intramural ganglia in diverticular disease of the colon. J Clin Pathol 18:40-42

9. Wedel T, Busing V, Heinrichs G, Nohroudi K, Bruch HP, Roblick UJ, Bottner M (2010) Diverticular disease is associated with an enteric neuropathy as revealed by morphometric analysis. Neurogastroenterol Motil 22(4):407-414, e493-404. https://doi. org/10.1111/j.1365-2982.2009.01445.x

10. Annibale B, Lahner E, Maconi G, Usai P, Marchi S, Bassotti G, Barbara G, Cuomo R (2012) Clinical features of symptomatic uncomplicated diverticular disease: a multicenter Italian survey. Int $\mathrm{J}$ Color Dis 27(9):1151-1159. https://doi.org/10.1007/s00384-0121488-5

11. Lembcke B (2015) Diagnosis, differential diagnoses, and classification of diverticular disease. Viszeralmedizin 31(2):95-102. https://doi.org/10.1159/000380833

12. Gan T, Yang JL, JC W, Wang YP, Yang L (2015) When and why a colonoscopist should discontinue colonoscopy by himself? World J Gastroenterol 21(25):7834-7841. https://doi.org/10.3748/wjg.v21. i25.7834

13. Schembre DB, Ross AS, Gluck MN, Brandabur JJ, McCormick SE, Lin OS (2011) Spiral overtube-assisted colonoscopy after incomplete colonoscopy in the redundant colon. Gastrointest Endosc 73(3):515-519. https://doi.org/10.1016/j.gie.2010.11.047

14. Hanson ME, Pickhardt PJ, Kim DH, Pfau PR (2007) Anatomic factors predictive of incomplete colonoscopy based on findings at CT colonography. AJR Am J Roentgenol 189(4):774-779. https:// doi.org/10.2214/AJR.07.2048

15. Raahave D, Christensen E, Loud FB, Knudsen LL (2009) Correlation of bowel symptoms with colonic transit, length, and faecal load in functional faecal retention. Dan Med Bull 56(2): $83-88$

16. Anderson JC (2015) Water-aided colonoscopy. Gastrointest Endosc Clin N Am 25(2):211-226. https://doi.org/10.1016/j.giec.2014.11. 002

17. Eickhoff A, Pickhardt PJ, Hartmann D, Riemann JF (2010) Colon anatomy based on CT colonography and fluoroscopy: impact on looping, straightening and ancillary manoeuvres in colonoscopy. Dig Liver Dis 42(4):291-296. https://doi.org/10.1016/j.dld.2009. 04.022

18. Gawron AJ, Veerappan A, Keswani RN (2014) High success rate of repeat colonoscopy with standard endoscopes in patients referred for prior incomplete colonoscopy. BMC Gastroenterol 14:56. https://doi.org/10.1186/1471-230x-14-56

19. Jung Y, Lee SH (2012) How do I overcome difficulties in insertion? Clin Endosc 45(3):278-281. https://doi.org/10.5946/ce.2012.45.3. 278

20. Luo M, Shan H, Zhou K (2002) CT virtual colonoscopy in patients with incomplete conventional colonoscopy. Chin Med J 115(7): $1023-1026$
21. Martinez F, Kondylis P, Reilly J (2005) Limitations of barium enema performed as an adjunct to incomplete colonoscopy. Dis Colon Rectum 48(10):1951-1954. https://doi.org/10.1007/s10350-0050140-7

22. Moreels TG, Macken EJ, Roth B, Van Outryve MJ, Pelckmans PA (2010) Cecal intubation rate with the double-balloon endoscope after incomplete conventional colonoscopy: a study in 45 patients. J Gastroenterol Hepatol 25(1):80-83. https://doi.org/10.1111/j. 1440-1746.2009.05942.x

23. Rex DK, Chen SC, Overhiser AJ (2007) Colonoscopy technique in consecutive patients referred for prior incomplete colonoscopy. Clin Gastroenterol Hepatol 5(7):879-883. https://doi.org/10.1016/ j.cgh.2007.03.015

24. Sato K, Shigiyama F, Ito S, Kitagawa T, Tominaga K, Suzuki T, Maetani I (2013) Colonoscopy using a small-caliber colonoscope with passive-bending after incomplete colonoscopy due to sharp angulation or pain. Surg Endosc 27(11):4171-4176. https://doi. org/10.1007/s00464-013-3016-2

25. Saunders BP, Halligan S, Jobling C, Fukumoto M, Moussa ME, Williams CB, Bartram CI (1995) Can barium enema indicate when colonoscopy will be difficult? Clin Radiol 50(5):318-321

26. Tan EJ, Soh KC, Ngiam KY (2013) Colonic architectural change on colonoscopy in patients taking psychotropic medications. Surg Endosc 27(5):1601-1606. https://doi.org/10.1007/s00464-0122636-2

27. Vemulapalli KC, Rex DK (2012) Water immersion simplifies cecal intubation in patients with redundant colons and previous incomplete colonoscopies. Gastrointest Endosc 76(4):812-817. https:// doi.org/10.1016/j.gie.2012.05.033

28. Wexner SD, Forde KA, Sellers G, Geron N, Lopes A, Weiss EG, Nogueras JJ (1998) How well can surgeons perform colonoscopy? Surg Endosc 12(12):1410-1414

29. Yucel C, Lev-Toaff AS, Moussa N, Durrani H (2008) CT colonography for incomplete or contraindicated optical colonoscopy in older patients. Am J Roentgenol 190(1):145-150. https://doi. org/10.2214/AJR.07.2633

30. Kantor J (1924) A clinical study of some common anatomical abnormalities of the colon. Am Roentgenray Soc 12:414-430

31. Ewing M (1975) Dolichocolon. ANZ J Surg 45(2):160-163

32. Liu R, Lin M, Yeh S (1989) Dolichocolon: an incidental finding on gallium scintigraphy. Clin Nucl Med 15(5):356

33. Madiba TE, Haffajee MR, Sikhosana MH (2008) Radiological anatomy of the sigmoid colon. Surg Radiol Anat 30(5):409-415. https://doi.org/10.1007/s00276-008-0344-3

34. Friedenwald J, Feldman E (1934) Clinical observations on the redundant colon (dolichocolon). South Med J XXVII(2):147-154

35. Brummer P, Seppala P, Wegelius U (1962) Redundant colon as a cause of constipation. Gut 3:140-141

36. Lane RH, Todd IP (1977) Idiopathic megacolon: a review of 42 cases. Br J Surg 64(5):307-310

37. Galambos A, Galambos W (1946) Redundancy of the colon. Am J Dig Dis 13(3):87-101

38. Muller-Lissner SA, Kamm MA, Scarpignato C, Wald A (2005) Myths and misconceptions about chronic constipation. Am J Gastroenterol 100(1):232-242

39. Ajao OG (1982) Differences between surgical colorectal conditions seen in the temperate and tropical regions. Dis Colon Rectum 25(8): 795-797

40. Autschbach F, Gassler N (2007) Idiopathic megacolon. Eur J Gastroenterol Hepatol 19(5):399-400. https://doi.org/10.1097/ MEG.0b013e3280116cb8

41. Kobak MW, Jacobson MA, Sirca DM (1962) Acquired megacolon in psychiatric patients. Dis Colon Rectum 5:373-377 
42. Koch TR, Schulte-Bockholt A, Otterson MF, Telford GL, Stryker SJ, Ballard T, Opara EC (1996) Decreased vasoactive intestinal peptide levels and glutathione depletion in acquired megacolon. Dig Dis Sci 41(7):1409-1416

43. Koch TR, Schulte-Bockholt A, Telford GL, Otterson MF, Murad TM, Stryker SJ (1993) Acquired megacolon is associated with alteration of vasoactive intestinal peptide levels and acetylcholinesterase activity. Regul Pept 48(3):309-319

44. Gattuso JM, Hoyle CH, Milner P, Kamm MA, Burnstock G (1996) Enteric innervation in idiopathic megarectum and megacolon. Int $\mathrm{J}$ Color Dis 11(6):264-271

45. Gattuso JM, Kamm MA, Talbot JC (1997) Pathology of idiopathic megarectum and megacolon. Gut 41(2):252-257

46. Lee J, Park H, Kamm M, Talbot I (2005) Decreased density of interstitial cells of Cajal and neuronal cells in patients with slowtransit constipation and acquired megacolon. J Gastroenterol Hepatol 20:1292-1298. https://doi.org/10.1111/j.1400-1746.2005. 03809.x

47. Meier-Ruge WA, Muller-Lobeck H, Stoss F, Bruder E (2006) The pathogenesis of idiopathic megacolon. Eur J Gastroenterol Hepatol 18:1209-1215
48. Wedel T, Van Eys GJ, Waltregny D, Glenisson W, Castronovo V, Vanderwinden JM (2006) Novel smooth muscle markers reveal abnormalities of the intestinal musculature in severe colorectal motility disorders. Neurogastroenterol Motil 18(7): 526-538. https://doi.org/10.1111/j.1365-2982.2006.00781.x

49. Iantorno G, Bassotti G, Kogan Z, Lumi CM, Cabanne AM, Fisogni S, Varrica LM, Bilder CR, Munoz JP, Liserre B, Morelli A, Villanacci V (2007) The enteric nervous system in chagasic and idiopathic megacolon. Am J Surg Pathol 31(3):460-468. https://doi.org/10. 1097/01.pas.0000213371.79300.a8

50. Ohkubo H, Masaki T, Matsuhashi N, Kawahara H, Yokoyama T, Nakajima A, Ohkura Y (2014) Histopathologic findings in patients with idiopathic megacolon: a comparison between dilated and nondilated loops. Neurogastroenterol Motil 26(4):571-580. https://doi. org/10.1111/nmo.12303

51. Gattuso JM, Smith VV, Kamm MA (1998) Altered contractile proteins and neural innervation in idiopathic megarectum and megacolon. Histopathology 33(1):34-38

52. Goulston E (1976) Diverticular disease of the colon and megacolon. Incidence in a psychiatric centre compared with a teaching hospital. Med J Aust 2(23):863-864 